\title{
MARKETING IMPLICATIONS OF FRAMING IN THE DECISION-MAKING
}

\author{
Peter Gál ${ }^{1}$ \\ ${ }^{1}$ Department of Strategy and Entrepreneurship, Faculty of Management, Comenius University in Bratislava, \\ Odbojárov 10, 82005 Bratislava, Slovakia
}

To cite this article: GÁL PETER. 2018. Marketing Implications of Framing in the Decision-Making. Acta Universitatis Agriculturae et Silviculturae Mendelianae Brunensis, 66(5): 1267-1273.

To link to this article: https://doi.org/10.11118/actaun201866051267

\begin{abstract}
Framing is a psychological concept closely related with decision-making. It says, that the way the information is served to the recipients, affects their opinion about a certain issue and, consequently, their decisions. Frame presents perception of the reality, since the limits of rationality often don't allow people to capture the reality in its complexity. Framing is manifested in several ways. The first relates to the starting point from which the reality is perceived. This dimension causes that people perceive differently the description of decision options formulated in terms of gains (positive frame) or losses (negative frame). The second dimension relates to the size or the width of the frame, i.e. whether the reality is seen from a wider or a narrower perspective. The aim of this study was to examine the impact of framing on the decision-making. The framing effect was studied by the analysis of answers to three problems, which were part of a broader questionnaire survey. The questionnaire was inspired or compiled from similar researches. The sample was 176 graduate university students (41\% men) of management major. The basic descriptive statistics and independent samples t-test were used for it. The results proved that the way the problem was framed to the respondents determined the outcomes of their decision-making. The implications both for the overall managerial decision-making and more specifically for the marketing practice are presented as well.
\end{abstract}

Keywords: framing, decision-making, psychological factors, prospect theory, marketing

\section{INTRODUCTION}

Bernoulli (1738/1954) first introduced the term expected utility, which served for replacement of the criterion of expected monetary value. Expected utility refers to the maximization of utility of the decision-maker rather than simply a maximization of the arithmetic average of the possible courses of action. Expected-utility theory suggests that each level of an outcome is associated with an expected degree of pleasure or net benefit, called utility. The expected utility of an uncertain choice is weighted sum of the utilities of the possible outcomes, each multiplied by its probability (Bazerman and Moore, 2009). This theory also included the principle of declining marginal utility of gains as well as the risk preferences of the decision-maker - risk-seeking or risk-averse. While expected utility depart from the logic of expected value, it provides a useful and consistent logical structure. Economists and decision researchers generally accepted the logic of the expected utility as rational behavior. However, it is rather a description, how choices are made by "econs" - purely economically considering individuals.

Kahneman and Tversky (1979) described several classes of choice problems in which the preferences systematically violated the axioms of expected 
utility theory. They pointed out the fact that Bernoulli's expected utility theory lacks the motive propulsion element, which is the reference point - the previous state to which the gains and losses are evaluated. According to their prospect theory, the reference point is important for the decision, people differently perceive gains and losses (they are loss-averse), and the subjective perception of the probabilities of the future conditions is distinct from their objective values (the principle of decreasing sensitivity). Prospect theory describes the fact, that even perceived differences based on a change in the "framing" of choices - in this case, from losses to gains - can dramatically affect how people decide. The way a problem is framed can profoundly influence the choices people make. Furthermore, people tend to adopt the frame as it is presented to them rather than restating the problem in their own way. According to Hammond et al. (1998), decision researchers have documented two basic types of frames that distort decision-making with particular frequency: frames as gains versus losses - the strikingly different responses reveal that people are risk averse when a problem is posed in terms of gains, but risk seeking when a problem is posed in terms of avoiding losses; and framing with different reference points - different reactions of people result from the different reference points presented in the frames. Framing is rather about the perception of the reality by people than about the reality itself. According to Hammond et al. (1998) a frame can establish the status quo or introduce an anchor. It can highlight sunk costs or lead you toward confirming evidence.

The influence of framing on the decision-making in the marketing was demonstrated by several studies. Ganzach and Karsahi (1995) examined the impact of message framing on buying behavior. They found, that the impact of the gain-framed message was much weaker than the impact of the loss-framed message.

According to Chen et al. (1998) price reduction framed in percentage terms seemed more significant for the low-price product than the same price reduction framed in dollar terms, and the opposite was true for the high-price product. They also found that coupon promotions were evaluated more favorably and were more effective in changing subjects' purchase intentions compared with the same savings in discount promotions.
Del Vecchio et al. (2007) found that frame affects consumers' perceptions of the promoted price and the weight they place on the promoted price. Their findings indicate that high-depth percentage-off promotions lead to higher post-promotion price expectations compared with cents-off promotions. Likewise, post-promotion choice is higher when high-depth promotions are framed in percentage-off - than cents-off terms.

Consumers compare a good's current price to a reference price (the last price they paid) and get more disutility from buying when prices have risen than the extra utility they get when prices have fallen. For orange juice, they estimated a coefficient of loss-aversion (the ration of loss and gain dis-utilities) around 2.4 (Camerer, 2000).

According to Thaler (1985), purchase decisions are affected by both acquisition utility and transactional utility. Acquisition utility describes the value people place on a commodity. Transactional utility refers to the quality of the deal that people receive, evaluated in reference to „what the item should cost". For example, to pay $€ 2.50$ for a coffee in small grocery store would bring higher negative transactional utility than to pay the same amount for a coffee in a fancy café at the promenade in the city center. One can argue that the inclusion of transactional utility in decision-making is not rational, but it does describe our behavior.

The aim of this paper is to examine the influences of framing effect on the perception of reality and to demonstrate its effect on the decision-making. The main research question this paper aims to answers is whether and how are students - prospective managers influenced by the framing. It also develops implications and recommendations for marketing practice and for consumer self-defense against it as well.

\section{MATERIALS AND METHODS}

The research was carried out at the Faculty of Management, Comenius University in Bratislava in year 2016. Its participants were 176 full-time first year master students of management major. The students were divided into two groups of similar size (Group A - 85 respondents, Group B - 91 respondents) to observe the difference in their responses to moderate variations of the questions. There were $41 \%$ men and 59\% women in the sample. The respondents were on

I: The basic demographic characteristics of the sample

\begin{tabular}{|c|c|c|c|c|c|c|c|c|c|}
\hline Whole sample & & $\#$ & Percent & Group A & $\#$ & Percent & Group B & $\#$ & Percent \\
\hline Sum & & 176 & $100 \%$ & & 85 & $100 \%$ & & 91 & $100 \%$ \\
\hline Men & & 72 & $41 \%$ & & 37 & $44 \%$ & & 35 & $38 \%$ \\
\hline Women & & 104 & $59 \%$ & & 48 & $56 \%$ & & 56 & $62 \%$ \\
\hline Average age & 23.00 & & & 23.11 & & & 22.90 & & \\
\hline St. dev. & 1.08 & & & 1.27 & & & 0.87 & & \\
\hline
\end{tabular}

Source: Own calculation 
average 23 years old, only with little deviations. There weren't significant differences between the basic demographic characteristics in the two groups of respondents (Tab. I). The students didn't have theoretical background about the surveyed issues yet. The own questionnaire, inspired by and compiled from similar researches, was used (Ariely, 2009; Bazerman and Moore, 2009; Hammond et al., 1998). The questionnaire consisted of 27 questions or problem descriptions. The questionnaire had two versions, which were similar, but not identical, i.e. The questions were slightly modified for both groups, but the core of the questions stayed the same. The questionnaire was created in Google forms application and each version was electronically distributed to one group of students during managerial decision-making classes under the supervision of a teacher. The respondents weren't allowed to use Internet or to discuss the answers with their peers. The questionnaire was focused on specific types of heuristics, biases and traps in managerial decision-making.

The obtained data were analyzed using the basic descriptive statistics in MS Excel for Problems $1-3$ and independent samples t-test for Problem 3 in statistical software package SPSS v.24. Results of the analysis are presented in structured tables that are further described and discussed.

The answers to the three following problems were explored:

\section{The Problem 1 description - The reference point (Purchase of discounted shoes)}

Question: Imagine that you go through the shopping mall, and suddenly you see the shoes in the shopping window, which you desired to buy for a long time. Would you buy them under the conditions listed below?

Group A: These shoes originally costed $€ 100$, but now they are on sale for $€ 70$ in the store.

Group B: The shoes originally costed $€ 100$, but currently the shop has a special discount and they cost only $€ 35$. Unfortunately, you don't have credit card or cash to buy them immediately. When you return to the store on the next day, you would find, that the special discount has expired, and the shoes are now on regular sale for $€ 70$.

\section{The Problem 2 description - The proper yardstick (Possibility to save $€ 15$ )}

Situation/Group A: You are buying a new bike helmet. At the current shop you are visiting, the type they offer to you for $€ 50$ fits you perfectly. However, you found on the Internet, that in another store at the other end of the city the same helmet is sold only for $€ 35$. Would you go there to buy it, to save $€ 15$ ?

Situation/Group B: You are buying a new electric bicycle. At the current shop you are visiting, the type they offer to you for $€ 1.500$ fits you. However, you found on the Internet, that in another store at the other end of the city the same bike is sold only for $€ 1.485$. Would you go there to buy it, to save $€ 15$ ?

Problem 3 - The added alternative, that changed the order of the previous alternatives (Selection of wine at different prices)

Question: Imagine that you go for a regular visit to your friend. Along the way, you stop in a small grocery store at the corner for a bottle of wine to bring him at least something. They offer you wines for different prices. Which bottle of wine would you choose?

Group A respondents could choose wine for $€ 3$, $€ 6, € 9$.

Group B respondents could choose wine for $€ 3$, $€ 6, € 9$ or $€ 18$ (the added alternative).

\section{RESULTS AND DISCUSSION}

The effect of framing on the decision-making is described and illustrated by respondents' answers on the following three problems.

\section{Problem 1 - The reference point (Purchase of discounted shoes)}

As can be seen in Tab. II, the respondents faced the question, whether to buy discounted pair of shoes for $€ 70$, while the original price for them was $€ 100$. In case the offer was formulated in this way, $80 \%$ of the respondents would buy them. However, if the shoes were short termly reduced to $€ 35$, only $34 \%$ of respondents would purchase them for the price of $€ 70$. The respondents' answers show that for the same price of $€ 70$, $80 \%$ of the respondents in one group would buy the shoes, whereas in the second group only $34 \%$ of respondents would buy them. The reference or starting points make the differences in these

II: Problem 1-respondents' answers by groups

\begin{tabular}{|c|c|c|}
\hline I would buy discounted shoes from $€ 100$ to $€ 70$ & $\#$ & Percent \\
\hline Group A & 85 & $100 \%$ \\
\hline Yes, I would buy them & 68 & $80 \%$ \\
\hline No, I wouldn't buy them & 17 & $20 \%$ \\
\hline Group B & 91 & $100 \%$ \\
\hline
\end{tabular}

Source: Own calculation 
groups. The reference point was $€ 100$ for the first group and thus the offer seemed interesting for most of the respondents. In the second group the respondents mentally moved from the original reference point of $€ 100$ to a new reference point of $€ 35$ and thus this offer didn't seem to be a bargain offer for most of them. At the same time, it shows that the respondents in the second group very quickly adopted the new reference point and were no longer willing to return to the previous reference point of $€ 100$.

It is confirmed, that people adjust to both positive and negative changes in circumstances with surprising speed, and then promptly forget that they did so (Gilbert et al., 1998). As Kahneman et al. (2006) state, we find ourselves on a hedonic treadmill in which we strive for an imagined happiness that forever slips out of our grasp, beckoning us onward.

This confirms the assumption of the prospect theory, that not only the current value of the parameter is substantial, as it was the price in this case, but equally important is also the reference point, that precedes this parameter's value. And just this reference point was vastly different for these two groups of respondents.

\section{Problem 2 - The proper yardstick (Possibility to save $€ 15$ )}

A rational decision as to whether to buy a helmet or electric bike on the other end of the city is to compare the achieved savings, which is in both cases the same - $€ 15$ with the costs, which represents the lost time and travel costs. Those $€ 15$ should compensate for the costs incurred for a trip to the other end of the town, which is in both cases the same. The respondents, addressing these situations $\mathrm{A}$ and $\mathrm{B}$, however decided differently, as can be seen in Tab. III. The majority of the respondents would go to the other end of the city to save $€ 15$, where they would save it on the helmet for $€ 50$, however, wouldn't go as far if they would save them on an electric bike for $€ 1$ 500. Most of the respondents compared therefore this amount with the price of the purchased goods, and the amount of savings perceived rather as a percentage of the total amount of the purchase (30\% vs. $1 \%$ ). If the respondents perceived this saving as a significant percentage, they were willing to exert some effort to get it.
This type of heuristics is largely used by retailers, who recently in their promotional flyers state the discounts both in absolute values as well as in percentages. They count with the fact, that a significant discount expressed as a percentage would attract the buyers, although the spared amount expressed in Euros may be quite low, even up to the minimum. It may not even compensate for the time and transportation costs to obtain that discount.

Similar example is provided by Russo and Schoemaker (1980). About $90 \%$ of questioned few hundred managers would travel two blocks away to save $\$ 30$ when buying a watch which originally costs $\$ 70$, but only $50 \%$ of the respondents would undertake this trip to achieve the same saving of $\$ 30$ when buying a video camera that costs $\$ 800$. They call this kind of problem the problem of the proper yardstick and state that all that counts is what you put in (or take out of) your pocket, which is dollars, not percentages (Russo and Schoemaker, 1980).

These types of problems clarify the importance of spending more time on a search when significant amounts of money are at stake and spending less time on a search for items of small value. Far too many people go to multiple grocery stores to save $\$ 10$ or $\$ 12$, while failing to search thoroughly for large purchases, such as which house to buy (Bazerman and Moore, 2009).

Problem 3 - The added alternative, that changed the order of the previous alternatives (Selection of wine at different prices)

An additional and by far the most expensive wine for $€ 18$ was added for the Group B to the fictional offer of wines (Tab. IV). Even only $2 \%$ of respondents have chosen this alternative, it has caused a change in the selection of the other alternatives. Respondents selected the cheapest alternative (wine for $€ 3$ ) to a lesser degree and their choice moved toward more expensive wines. The mean price of the offered wines was $€ 6$ in the Group A and $€ 9$ in the Group B, which represents an increase of $50 \%$ in the wines' mean price.

Because the standard deviations for the two groups are similar (1.63 and 2.46), the equal variances assumed test was used (Tab. V). The observed $\mathrm{t}$-value is -2.629 , with degrees of freedom equal to

III: Problem 2 - respondents' answers by groups

\begin{tabular}{lcc}
\multicolumn{1}{c}{ The possibility to save $€ \mathbf{1 5}$ when buying at the other end of the city } & $\#$ & Percent \\
\hline Situation/Group A & 85 & $100 \%$ \\
Yes, I would buy it in the shop on the other end of the city & 76 & $89 \%$ \\
No, I would buy it in the current shop I am & 9 & $11 \%$ \\
\hline Situation/Group B & 91 & $100 \%$ \\
Yes, I would buy it in the shop on the other end of the city & 21 & $23 \%$ \\
No, I would buy it in the current shop I am & 70 & $77 \%$ \\
\hline
\end{tabular}

Source: Own calculation 
IV: Problem 3 - respondents' answers by groups

\begin{tabular}{|c|c|c|}
\hline Wine for your friend & $\#$ & Percent \\
\hline Group A & 85 & $100 \%$ \\
\hline \multicolumn{3}{|l|}{ Price } \\
\hline$€ 3$ & 17 & $20 \%$ \\
\hline$€ 6$ & 58 & $68 \%$ \\
\hline$€ 9$ & 10 & $12 \%$ \\
\hline Group B & 91 & $100 \%$ \\
\hline \multicolumn{3}{|l|}{ Price } \\
\hline$€ 3$ & 11 & $12 \%$ \\
\hline$€ 6$ & 57 & $63 \%$ \\
\hline$€ 9$ & 21 & $23 \%$ \\
\hline$€ 18$ & 2 & $2 \%$ \\
\hline
\end{tabular}

Source: Own calculation

V: Problem 3 - Independent Samples t-Test Group Statistics

\begin{tabular}{lccccc}
\hline & Group & N & Mean & Std. Deviation & Std. Error Mean \\
\hline \multirow{2}{*}{ Price } & A & 85 & 5.75 & 1.683 & 0.183 \\
& B & 91 & 6.59 & 2.458 & 0.258 \\
\hline
\end{tabular}

Source: Own calculation

VI: Problem 3 - Independent Samples t-Test Results

\begin{tabular}{cccccccc}
\hline \multicolumn{7}{c}{ t-test for Equality of Means (Equal variances assumed) } \\
\hline & $\mathrm{t}$ & $\mathrm{df}$ & $\begin{array}{c}\text { Sig. } \\
\text { (2-tailed) }\end{array}$ & $\begin{array}{c}\text { Mean } \\
\text { Difference }\end{array}$ & $\begin{array}{c}\text { Std. Error } \\
\text { Difference }\end{array}$ & 95\% Confidence Interval of the Difference \\
Price & -2.629 & 174 & 0.009 & -0.840 & 0.320 & Lower & Upper \\
\hline
\end{tabular}

Source: Own calculation

174 (Tab. VI). The two-tailed probability of 0.009 is less than 0.01 and, therefore, the test is considered statistically significant at the 0.01 level.

As can be seen in Tab. VI, there is a statistically significant difference between the mean price for the Group A and the Group B ( $t=-2.629, \mathrm{p}=.009)$. The Group B had a statistically significantly higher mean price of purchased wine (6.6) than the Group A (5.8). This represents an increase of $14 \%$ in the mean price of the purchased wine.

The Group B had a broader decision-making frame or a broader context then the Group A. It seemed more appropriate to the respondents to select wines that are somewhere in the middle of the offer. This is a simplified heuristic approach for choosing the winning alternative. Similar approaches report also Goodwin and Wright (2014). This approach might be also connected with a tendency to direct to the mean for certain types of decisions, which is described in a slightly different context (Kahneman, 2011; Mauboussin, 2012). This suggests that it is favorable for retailers to offer a broader portfolio of products or services, including the so-called premium. The Internet especially allows them to offer such a long-tail portfolio. Although only a small percentage of customers would select the premium product or service, it will affect their choice toward the selection of more expensive alternatives. When buying Internet services, you often see three types of subscription plans, low, standard and high, which might also be associated with this phenomenon. A similar strategy is used also by car manufacturers, who offer by certain car models multiple levels of equipment or special models and they also sell some cars under several different brand names, some of which are sport or premium oriented.

\section{CONCLUSION}

The research implications could be divided into two categories - for marketing practice and for the customers' self-defense. To assess the bargain of the offer, the reference point is very important, i.e. the price, for which the product or service was originally offered. Customers compare this starting price with the price they actually should pay. For them is not defining just the price, which really departs from their wallet or account, but also its embedding in a specific context. In reality it may not even be obvious, whether the product or service was ever sold at that reference price. Implication 
for the retailers is to use high starting prices and discounts, crossed-out prices on the price tags or the Internet offers. Customers should be focused on the acquisition utility and consider the price, which really departs from their wallet.

Customers like discounts and often link them only to the offered product itself, but don't look to the spent effort and costs, which must be incurred to get the discounted product. Especially interesting for them are high discounts expressed as a percentage even at relatively cheap products. The total saved amount of money could be quite low and doesn't even have to cover the increased costs, which relate to the achievement of this rebate, like transportation costs, time, etc. That is why retailers should state high discounts at cheap products expressed as a percentage and at relatively expensive products as currency $(€, \$)$. Customers on the other hand should focus in their buying decisions on their priorities and compare the saved amount with the costs to achieve it.

In case of the offers, where there is available a broader portfolio for different prices of one type of product or service, customers might tend to converge to the mean and search for an offer that is in the middle of that portfolio. The addition of more expensive product into the portfolio, that hardly anyone chooses and certainly doesn't pose a winning alternative may push the average price of the bought products upward and lead to the increased turnover of traders. To increase their turnover and margin, it is recommended for the retailers to add more expensive products in their portfolio. Customers should focus more on the basic functions the product should fulfill and think twice about buying premium products for higher prices and the necessity of the added frills.

The gender differences in the responses haven't been due to the relatively small size of the sample subject of this study. However, gender seems to play difference in the framing effects and task domains moderate these gender differences in these effects. Scenarios in the monetary domain cause more framing effects in males than females, while scenarios in the life-death domain do the opposite. The gender effect in the monetary domain isn't obviously as significant as in the life-death domain. This may be due to the fact that money is also important for woman, which decreases the gender differences in the monetary domain (Huang and Wang, 2010). Since questions in this study were from the monetary domain and women had a slight dominance in the sample, it is evident from the results, that they were like men also affected by the framing effect. Concerning the marketing implications, the inclusion of demographic characteristics such as gender, age or education level seems reasonable for retailers. The promotional messages could be framed separately for different market segments and it is expected to result in different outcomes (Cheng and $\mathrm{Wu}, 2010$ ).

This research shows simple and quite effective ways of people's judgment manipulation through the presentation of information in a particular context. If they function well on relatively educated students, their impact on the other, less educated population, may be even more noticeable. The manipulation of the judgment may be noticeable also in other information processing context, not just in the specific area of marketing. Even experienced managers showed the same bias as did students' decisions and were no better than students in utilizing information relevant to rational inventory stocking (Bolton et al. 2012). According to other authors, experienced respondents do not show the basic framing effect demonstrated with students. The more experienced respondents also believed, that strategic decision-making is characterized by additional components, which haven't been manipulated in the framing task (Wright and Goodwin, 2002).

As for limitations of this study, the size of the sample of the survey may imply some questions about its relevance. Similarly large or small samples were used also by the prominent authors, like the Nobel prize laureate for economy Daniel Kahneman who published together with Amos Tversky (Tversky and Kahneman, 1981) and their path-breaking research provided the intellectual foundation for studying the psychological aspects of decision-making, recent Nobel prize 2017 laureate Richard Thaler, other professors like Max Bazerman, Edward Russo, Paul Shoemaker, who published several books and numerous academic articles in this field and the results of their researches are frequently cited. Another limitation might be the existence of a difference between what people say they would do and what they actually do in reality.

Findings from this article can provide a corner stone for further and more detailed research in the area of information processing as an integral part of decision-making process and the factors that influence it. Further research might focus on real decisions, e.g. in the environment of online shops or on different student populations (with different majors of study or from different nations) as they might have different personality attributes and characteristics (Holienka and Holienkova, 2014) and thus could show different results.

\section{REFERENCES}

ARIELY, D. 2009. Predictably Irrational: The Hidden Forces That Shape Our Decisions. New York: HarperCollins. BAZERMAN, H. M. and MOORE, A. D. 2009. Judgment in Managerial Decision-making. Hoboken: John Wiley \& Sons. 
BERNOULLI, D. 1954. Exposition of a New Theory on the Measurement of Risk (1738). Econometrica, 22(1): 23-36. BOLTON, G. E., OCKENFELS, A. and THONEMANN, U. 2012. Managers and students as newsvendors. Management Science, 58(12): 2225-2233.

CAMERER, C. F. 2000. Prospect theory in the wild: Evidence from the field. In: KAHNEMAN, D. and TVERSKY, A. (Eds.). Choices, Values and Frames. New York: Russell Sage Foundation, pp. 148-161.

CHEN, S. F. S., MONROE, K. B. and LOU, Y. C. 1998. The effects of framing price promotion messages on consumers' perceptions and purchase intentions. Journal of Retailing, 74(3): 353-372.

CHENG, F. F and WU, C. S. 2010. Debiasing the framing effect: The effect of warning and involvement. Decision Support Systems, 49(3): 328-334.

DELVECCHIO, D., KRISHNAN, H. S. and SMITH, D. C. 2007. Cents or percent? The effects of promotion framing on price expectations and choice. Journal of Marketing, 71(3): 158-170.

GANZACH, Y. and KARSAHI, N. 1995. Message framing and buying behavior: A field experiment. Journal of Business Research, 32(1): 11-17.

GILBERT, D. T. et al. 1998. Immune Neglect: A Source of Durability Bias in Affective Forecasting. Journal of Personality and Social Psychology, 75(3): 617-638.

GOODWIN,P. and WRIGHT, G. 2014. Decision Analysis for Management Judgment. $5^{\text {th }}$ Edition. Chichester:J. Wiley.

HAMMOND, J. S., KEENEY, R. L. and RAIFFA, H. 1998. The Hidden Traps in Decision-making. Harvard Business Review, 76(5): 47-58.

HOLIENKA, M. and HOLIENKOVA, J. 2014. Enterprising Tendencies of Management and Psychology Students : Differences and Common Attributes. Comenius Management Review, 8(1): 39-52.

HUANG, Y. and WANG, L. 2010. Sex differences in framing effects across task domain. Personality and Individual Differences. 48(5): 649-653.

KAHNEMAN, D. 2011. Thinking, Fast and Slow. New York: Farrar, Straus and Giroux.

KAHNEMAN, D. et al. 2006. Would You Be Happier If You Were Richer? A Focusing Illusion. Science, 312(5782): 1908-1910.

KAHNEMAN, D. and TVERSKY, A. 1979. Prospect Theory: An Analysis of Decisions under Risk. Econometrica, 47(2): 262-292.

MAUBOUSSIN, M. J. 2012. Think twice: Harnessing the power of Counterintuition. $2^{\text {nd }}$ Edition. Boston: Harvard Business Review Press.

RUSSO, E. J. and SCHOEMAKER, P. J. H. 1980. Decision Traps. New York: Fireside.

THALER, R. H. 1985. Mental Accounting and Consumer Choice. Marketing Science, 4(3): 199-214.

TVERSKY, A. and KAHNEMAN, D. 1981. The Framing of Decisions and the Psychology of Choice. Science, 211(4481): 453-458.

WRIGHT, G. and GOODWIN, P. 2002. Eliminating a framing bias by using simple instructions to 'think harder' and respondents with managerial experience: Comment on 'breaking the frame'. Strategic Management Journal, 23(11): 1059-1067. 